\title{
Culture and Psychopathology: Foundations, Issues, Directions
}

\author{
Anthony J. Marsella, ${ }^{1}$ and Ann Marie Yamada ${ }^{2}$ \\ ${ }^{1}$ Department of Psychology, University of Hawaii, United States of America \\ 2 School of Social Work, University of Southern California, United States of America
}

\begin{abstract}
The present article offers an overview of the historical influences, conceptual assumptions, and
major findings and issues associated with the study of culture and psychopathology. The article traces continuing reductionistic resistance to the incorporation of cultural considerations in the etiology, expression, and treatment of psychopathology to historical and contemporary forces. These forces include 'cultural context' of Western psychiatry and psychology, which choose to locate the determinants of behaviour in the human mind and brain. A definition of culture that acknowledges its internal and external representations is offered, and steps in the cultural construction of reality are proposed. Within this context, the risks of imposing Western cultural views universally are noted, especially attempts to homogenise classification and diagnostic systems across cultures. 'Culturebound' disorders are used as example of Western bias via the assumption that they have 'real' disorders, while the other cultures have disorders that are shaped by culture. Cultural considerations in understanding the rate, etiology, and expression are presented, including recommended criteria for conducting epidemiological studies across cultural boundaries, especially 'schizophrenic' disorders as this problematic diagnostic category is subject to multiple cultural variations. The article closes with discussions of 'cultural competence' and 'multilevel' approaches to behaviour.
\end{abstract}

Keywords: culture, mental health, psychopathology, native Hawaiians, culture-bound disorders, diagnosis, healing

\section{Foundations}

\section{Some Historical Considerations}

In 1904, Professor Emil Kraepelin (1856-1926), the acknowledged father of modern psychiatry, reported that his classification and diagnostic system, developed and refined in 19th century Europe (e.g., dementia praecox, manic-depressive disorders), appeared to have little applicability to certain non-Western groups in Southeast Asia and the Lakotah Indian tribes in the United States that he visited as part of a global lecture tour. This limitation posed a serious challenge to efforts to advance a psychiatric classification system that would be universally applicable. To his credit, Kraepelin (1904) recognised that the cultural background of the patients needed to be considered in arriving at a valid diagnosis. He then proposed a new psychiatric specialty - Vergliechende Psychiatrie - Comparative Psychiatry. He wrote:
The characteristics of a people should find expression in the frequency as well as the shaping of the manifestations of mental illness in general; so that comparative psychiatry shall make it possible to gain valuable insights into the psyche of nations and shall in turn also be able to contribute to the understanding of pathological psychic processes. (1904, p. 9)

Kraepelin's brilliant insights and his proposal on the role of cultural factors in the frequency and manifestation of mental disorders were not unique, but reflected a growing interest in the role of culture as a determinant of human behavior in previous centuries. For example, the writings of many 18 th and 19th century philosophers and social commentators such as Jean Jacques Rousseau (1704-1788), Karl Marx (1818-1883), Fredrich Engels (1820-1895), and Emile Durkheim (1858-1917), all pointed to the socio-cultural milieu as an important determinant of individual and collective behavior. The well-known words of Rousseau come readily to mind when he asserted: '... Man is by nature 
good, it is only our institutions that have made him bad' (Durant \& Durant, 1967, p. 19). These words launched the Romanticist movement and raised questions about the role of civilization and 'madness'.

The thoughts of this group of social philosophers were given new authority and relevance within psychiatry with the subsequent work of the founder of psychoanalysis, Sigmund Freud (1856-1939), who indicted society as a major source of neuroses and other psychological dysfunctions in his definitive work, Civilization and Its Discontents (1930). When Freud juxtaposed human biological impulses (i.e., id/nature) against the constraints of conscience (i.e., superego/society), he captured the complex tensions of cultural socialisation in the life experiences of individuals. It is through a process of cultural socialisation via familial and community rewards/punishments, modelling, and selective exposures to beliefs and practices, that culture comes to construct our realities, and to help determine and shape our behavior within our unique temperament and common anatomy.

Yet, in spite of the broad endorsement of the sociocultural perspective across the decades, including by support from some of psychiatry's most famous figures, the socio-cultural perspective was widely dismissed by many others in psychiatry, who were committed to reductionistic approaches that located the causes, manifestations, and cures of mental disorders in the brain and nervous system. Indeed, Freud's own mentors, Ernst von Brucke (1819-1892), and Emil Dubois Reymond (1818-1896), claimed that there are 'No other forces than the common physical-chemical ones are active within the organism' (Jones, 1953, p. 40).

As a result, many psychiatrists concluded that mental disorders were neuropsychiatric diseases, universal in nature, and free of any substantive socio-cultural determinants. This was especially the case for 19th-century Europe, where the biological foundations of psychiatry had gained a firm foothold via the teachings of the Germans psychiatrists Wilhelm Griesinger (1817-1868) and Emil Kraepelin (1856-1926) and others whose medical approaches resisted the popular 'psychodynamic' approaches that took hold in the United States and remain to the present day.

Biological approaches would gain further support in psychiatry in the United States with the development of tranquilizers and anti-depressant medications in the 1960 s and 1970s, and with the leadership of Gerald Klerman, professor of psychiatry at Harvard University, and former director of the National Institute of Mental Health during this period. Klerman and his colleagues sought to break the hold of psychodynamic practitioners and psychologists by advancing what has been termed by some as a 'neo-Kraepelian' conspiracy (e.g., Blashfield, 1984). Klerman proposed that psychiatry needed to reestablish itself as a medical specialty and to focus upon the biological substrates of mental illness. But it is noteworthy that Klerman's success in moving psychiatry toward a 'medical model' of mental disorders reflects the very role of disciplinary 'cultures' in shaping thought and practice via leader-based conceptual biases and preferences. This thought does not deny the fact that sound scientific research contributed to changes, but rather that 'power' in shaping thought and practice does often stem from individual biases.

To be sure, there were those within psychiatry through the early 20th century who continued to argue about the importance of socio-cultural factors for our understanding of the etiology, manifestations, and treatment of mental disorders. For example, Georges Devereux coined the terms 'primitive psychiatry', 'ethnopsychiatry', and 'psychiatric anthropology' in a series of publications throughout the 1940s and 1950s. Other pioneer figures include Eric Wittkower, H.B.M. Murphy, and Raymond Prince at McGill University in Canada, Arie Kiev in New York, Alexander Leighton at Cornell and Harvard, and Tsung-Li Lin at WHO. All of these figures made significant efforts to advance the socio-cultural perspective, especially through international studies that revealed variations in rates and expressions of mental disorders. They were joined in their efforts by anthropologists of the era like Ruth Benedict, Margaret Mead, and Ralph Linton, who called attention to the relativity of 'normality', and to the power of culture in shaping normal and disordered behaviour.

However, it was not until the pioneering efforts of Arthur Kleinman at Harvard University and Laurence Kirmayer at McGill University that the psychiatric specialties of 'transcultural psychiatry' and 'cultural psychiatry' gained widespread acceptance, including the development of special residency training programs. There work was followed by major contributions from a number of minority psychiatrists, including Juan Mezzich and Horatio Fabrega, whose efforts facilitated the inclusion of the cultural criteria for diagnosis in the American Psychiatric Association's Diagnostic and Statistical Manuals (DSMs), after years in which psychiatry seemed to ignore socio-cultural factors. Two volumes by Arthur Kleinman (Kleinman, 1980; Kleinman \& Good, 1996) crystallised much of the research and conceptual literature and helped establish the field. It is noteworthy that Arthur Kleinman is both a psychiatrist and anthropologist, and this combination of training enabled him to better articulate the role of culture.

Yet another important event in the shaping of the study of culture and psychopathology came via the United States Department of Health and Human Services in its published report entitled Mental Health: Culture, Race, and Ethnicity (2001). In this report, the DHHS reached specific conclusions about the role of culture and forcefully stated 'Culture counts!' The report detailed disparities in the provision of psychiatric ser- 
vices to racial and ethnic minorities in the United States and called for renewed efforts to address these problems. The report states:

The main message of this supplement is that 'culture counts' The cultures that patients come from shape their mental health and affect the types of mental health services they use. Likewise, the cultures of clinician and the service system affect diagnosis, treatment, and the organisation and financing of services. Cultural and social influences are not the only influences on mental health and service delivery, but they have been historically underestimated - and they do count. Cultural differences must be accounted for to ensure that minorities, like all Americans, receive mental health care tailored to their needs. (DHHS, 2001, p. 14)

Among the social and behavioral sciences, credit must given to a number of early anthropologists whose entry into the field brought credible theoretical and research contributions (e.g., William Caudill, Byron Good, William Lebra, Takie Lebra). Within psychology, advances in the field occurred via the work of Juris Draguns, Stanley Sue, and Anthony J. Marsella in clinical psychology, and Paul Pedersen, Alan Ivey, and Derald Sue in counseling psychology. Counselling psychology, in fact, was the discipline that made many contributions to ethnic minority psychology. Key figures in various ethnic groups include Derald Sue and Fred Leong (Chinese), Teresa LaFramboise and Joseph Trimble (American Indian), Patricia Arredondo, Lillian Comas Diaz (Latino), and Anthony Franklin and Thomas Parham (African American). The list of names could, of course, be extended to include numerous others. However, these names help document the historical progress that has occurred as cultural factors assumed a recognised and acknowledged dimension of the mental health professions and sciences.

Today, articles on the history of culture and psychopathology - the name now preferred by many because of its independence from a particular discipline or profession - document the course of historic changes in greater detail (e.g., Marsella, 1996; Fabrega, 2001). Space constraints in the present article limit the extensive literature on culture and psychopathology that now exists. Readers are encouraged to see Draguns (2006), Lopez and Guarnaccia (2008), and Marsella and Yamada $(2002,2007)$ for detailed reviews.

\section{The Concept of Culture}

Efforts to advance the socio-cultural perspective were obviously contingent on an understanding of the term 'culture'. And like so many terms that were used widely in both the 'popular' and 'professional' vernaculars, 'culture' had many surplus meanings that interfered with theory and research (e.g., see Kluckholm \& Kroeber, 1952, for a listing of 100 early definitions of culture). Although the term 'culture' continues to be used widely today to mean many different things from the arts (i.e., music, dance, drama, paintings) to a quality of personal- ity ('She is cultured'), its meaning for the study of human behavior is much more specific, and goes beyond the popular vernacular to a more technical definition. For current purposes, we will define culture as the following:

Culture is shared learned behavior and meanings that are socially transmitted for purposes of adjustment and adaptation. Culture is represented externally in artificats (e.g., food, clothing, music), roles (e.g., the social formation), and institutions (e.g., family, government). It is represented internally (i.e., cognitively, emotionally) by values, attitudes, beliefs, epistemologies, cosmologies, consciousness patterns, and notions of personhood. Culture is coded in verbally, imagistically, proprioceptively, viscerally, and emotionally resulting in different experiential structures and processes.

Thus, culture is the lens or template we use in constructing, defining, and interpreting reality. This definition suggests that people from different cultural contexts and traditions will define and experience reality in very different ways. Thus, even mental disorders must vary across cultures because they cannot be separated from cultural experience. Marsella (1982) stated:

We cannot separate our experience of an event from our
sensory and linguistic mediation of it. If these differ, so must
the experience differ across cultures. If we define who we are
in different ways (i.e., self as object), if we process reality in
different ways (i.e., self as process), if we define the very
nature of what is real, and what is acceptable, and even what
is right and wrong, how can we then expect similarities in
something as complex as madness. (1982, p. 363) It should also be noted that the very languages that we use in mediating reality critically structure our reality and thus shape our behavior. For example, Marsella (1985) noted that languages vary in their reliance and use on metaphorical terms and this results a different sensory mediation of reality by presenting immediate imagistic and felt experiences rather than detached abstractions:

In this respect, a metaphorical language provides a rich and immediate sensory experience of the world which is not diluted by being filtered through words which distantiate the cognitive understanding from the experience. In a metaphorical language system, the understanding and the language are one. (Marsella, 1985, p. 292)

So how is it that our cultural constructions of reality are created? Our worldviews - our cultural templates for negotiating reality - emerge from our inborn human effort to pursue meaning via the brain's functions of seeking, taking in, and organising information into coherent units. The brain inherently and reflexively provokes us to describe, understand, predict, and control the world about us through the ordering of stimuli into complex belief and meaning systems that negotiate our perceptions and our milieu by guiding behavior. Our brain not only responds to stimuli from the earliest moments following birth (indeed, also in utero), it also organises, connects, and symbolises them, and in this process, generates patterns of explicit and implicit 
meanings and purposes that serve to promote survival, growth, and development. This process occurs, as noted previously, through cultural socialisation. Thus, what is 'universal' is the brain and its reflexive tendency to process information from its milieu. What is relative is the social contexts in which we exist, and the content and process that serves as the foundations for our constructions of reality.

\section{Western Psychiatry, Clinical Psychology and Related Disciplines Are Cultural Constructions: They Are Not Universal}

Somewhere along the way, amid the ethnocentric blindness that is so reflexive in all cultures to the realities of others, it is essential we recognise that Western mental health professions and sciences are 'cultural constructions'. As such, they must be seen as relative to the historical, linguistic, and socio-political influence of Western cultural traditions, and as such, they should not be considered 'objective', but rather representations of cultural knowledge and practice (e.g., ontogenies, epistemologies, praxiologies) rooted within Western cultural traditions (e.g., Marsella, 2009). Unfortunately, the powerful political, economic, and cultural influences of Western nations promote the widespread acceptance of Western psychiatry fostering a pseudo global homogeneity in psychiatry. This homogeneity is further supported and promoted by leaders at institutions like the World Health Organization, where officials - all of whom are either Western or trained in Western medical traditions - the National Institute of Mental Health, and various medical and pharmaceutical scientific and commercial interests whose biases limit their criteria for accuracy (e.g., Higginbotham \& Marsella, 1988).

As a result, the indiscriminate application and imposition of Western psychiatry is subject to question and criticism, and much of this growing criticism is being generated by non-Western psychiatrists who are resisting Western cultural hegemony. For example, consider the powerful words of the Asian Indian psychiatrist Chakraborty (1991), who wrote:

Even where studies were sensitive, and the aim was to show relative differences caused by culture, the ideas and tools were still derived from a circumscribed area of European thought. This difficulty still continues and, despite, modifications, mainstream psychiatry remains rooted in Kraepelin's classic 19th century classification, the essence of which is the description of the two major 'mental diseases' seen in mental hospitals in his time - schizophrenia and manic depression. Research is constrained by this view of psychiatry. A central pattern of (western) disorders is identified and taken as the standard by which other (local) patterns are seen as minor variations. Such a construct implies some inadequacy on the part of those patients who fail to reach 'standard'. Though few people would agree with such statements, there is evidence of biased, value-based, and often racist undercurrents in psychiatry.... Psychiatrists in the developing world ... have accepted a diagnostic framework developed by Western medicine, but which does not seem to take into account the diversity of behavioral patterns they encounter. (p. 1204)

This recognition of ethnocentric bias has, for obvious reasons, been the source of considerable argument and debate. There is a reluctance to admit that one's worldviews are not universal, whether in religions, politics, or daily values and practices. Thus, Western psychiatric assumptions and practices may be relevant and accurate within a Western cultural context, but this does not mean they are relevant or accurate in other cultural contexts. We must not mistake 'power' and 'dominance' for accuracy.

\section{Culture, Classification, and Diagnosis Issues in Classification and Diagnosis}

Within psychology, the academic and disciplinary fields of cross-cultural psychology, cultural psychology, indigenous psychology, and various ethnic minority psychologies have all provided extensive research support to document the role of culture in shaping human behaviour. When added to the research in transcultural psychiatry, cultural psychiatry, psychiatric anthropology, and others, it is now widely accepted that continued efforts that ignore cultural variations constitute erroneous and pernicious ethnocentric biases that risk serious mistakes in clinical practices and research (e.g., Marsella, 2009, Marsella \& Yamada, 2007; Paniagua, 2001) ). Fortunately, even the DSM IV-TR (APA, 2000) now points out the risks of ignoring a person's culture:

A clinician who is unfamiliar with the nuances of an individual's cultural frame of reference may judge incorrectly judge as psychopathology those normal variations in behavior, belief, and experience that are particular to the individual's culture ... Applying [Certain diagnostic criteria and categories] across cultural settings may be especially difficult because of wide cultural variation in concepts of self, styles of communication, and coping mechanisms. (American Psychiatric Association, 2000, p. XXXIII)

\section{Cultural Criteria for Formulating a Case}

In an effort to increase sensitivity to cultural variations, the DSM further offers a series of criteria (albeit in its very last pages: pages $897-898$ out of 943 pages) for the cultural formulation of a case and a listing of 'culturebound syndromes'. The criteria include determining the (1) cultural identity of the individual, (2) cultural explanations of the individual's illness, (3) cultural factors related to the psychosocial environment and levels of functioning, (4) cultural elements of the relationship between the individual and clinician, and (5) overall cultural assessment for diagnosis and care. Theoretically, these criteria should be used in each and every case since each case is a 'cultural' encounter between the different cultures of the patient and professional. This especially true today as we now find patients from so many different ethnocultural groups (e.g., Chinese, Mexican, Nigerian, Vietnamese, WASP) seeking care from profes- 
sionals from so many different ethnocultural groups (e.g., Filipino, Iranian, Israeli, Korean, WASP). Assessing sociocultural issues is one step in designing culturally relevant and empirically supported practices as it a foundation for examining the relevance of interventions across groups and also generates knowledge that can be used to develop culturally-tailored interventions (Yamada \& Brekke, 2008).

\section{Culture-Bound Disorders}

One of the problematic topics for Western classification and diagnosis is the issue of culture-bound disorders (e.g., APA DSM IV TR, 2000; Marsella, 2000; Simon \& Hughes, 1989). Examples of these disorders are displayed in Table 1. While some favouring universal views of psychiatric disorders claim that these disorders are merely variants of Western disorders contextualised in non-Western cultures, here, the question must be asked: Why is it that the non-Western disorders are contextualised in non-Western cultures, but those identified and coded in the West in DSMs and ICDs are the real thing? Certainly, they are as much cultural products and are those from non-Western cultures. Marsella (2000) summarises many of the arguments and issues regarding culture-bound disorders.

\section{An Example from Native Hawaiian Culture and Behavior}

The Native Hawaiian people (Kanaka Maoli) provide an excellent example of an indigenous theory of maladjustment and dyfunction, and its relationship to cultural worldviews and traditions (see Higginbotham et al, 1987; Marsella, Oliviera, Plummer, \& Crabbe, 1995; McCubbin \& Marsella, 2009). The Native Hawaiian culture considers all of its people to be embedded within a complex ecology of relationships among gods, nature, and family, and person (see Figure 1). Harmony (Lokahi) across these elements occurs as long as a person meets his/her individual, familial, environmental, and spiritual responsibilities. The cultural system is based on an ethos of preserving the social fabric of the group through a well-developed series of beliefs about expected behaviors and about behaviors that interfere or harm the social fabric.

Within this framework, health and illness are considered to be a function of those forces that serve to either promote or to destroy harmony. Given the importance of the complex social fabric for Native Hawaiians, many of these forces reside in events and behaviors that support or undermine social and spiritual relations. For example, things that destroy the social fabric include the following behaviors:

$$
\begin{aligned}
& \text { - Hate (ina'ina) } \\
& \text { - } \text { Jealousy (lili) } \\
& \text { - } \text { Budeness (ho'okano) } \\
& \text { - Bearing a grudge (ho'omauhala) } \\
& \text { - Bragging (ha'anui) } \\
& \text { - Showing off (ho'oi'o) }
\end{aligned}
$$

\begin{tabular}{|c|c|}
\hline Name & Definition and cultural and geographical location \\
\hline Amok & $\begin{array}{l}\text { Sudden outburst of explosive and assaultive violence preceded by period of social withdrawal and apathy (Southeast Asia, } \\
\text { Philippines) }\end{array}$ \\
\hline Ataque de Nervios & $\begin{array}{l}\text { Uncontrollable shouting and/or crying. Verbal and physical aggression. Heat in chest rising to head. Feeling of losing control. } \\
\text { Occasional amnesia for experience (Caribbean Latinos and South American Latinos). }\end{array}$ \\
\hline Hwa-Byung & Acute panic, fear of death, fatigue, anorexia, dyspnea, palpitations, lump in upper stomach (Korea). \\
\hline Latah & $\begin{array}{l}\text { Startle reaction followed by echolalia and echopraxia, and sometimes coprolalia and altered consciousness (Malaysia and } \\
\text { Indonesia). }\end{array}$ \\
\hline Koro (Shook yong) & $\begin{array}{l}\text { Intense fear following perception that one's genitalia (men/women) or breasts (women) are withdrawing into one's body. } \\
\text { Shame may also be present if perception is associated in time with immoral sexual activity (Chinese populations in Hong Kong } \\
\text { and Southeast Asia). }\end{array}$ \\
\hline Phii Pob & Believes one is possessed by a spirit. Numbness of limbs, shouting, weeping, confused speech, shyness (Thailand). \\
\hline Pissu & Burning sensations in stomach, coldness in body, hallucinations, dissociation (Ceylon). \\
\hline Suchi-bai & $\begin{array}{l}\text { Excessive concerns for cleanliness (changes street clothes, washes money, hops while walking to avoid dirt, washes } \\
\text { furniture, remains immersed in holy river (Bengal, India - especially Hindu widows). }\end{array}$ \\
\hline Susto (Espanto) & $\begin{array}{l}\text { Strong sense of fear that one has lost their soul. Accompanied by anorexia, weight loss, skin pallor, fatigue, lethargy, } \\
\text { extensive thirst, untidiness, tachycardia, and withdrawal (Latinos in South and Central America, Mexico, and Latino } \\
\text { migrants to North America). }\end{array}$ \\
\hline Taijin Kyofusho & Intense fear of interpersonal relations. Belief that parts of body give off offensive odors or displease others (Japan). \\
\hline Tawatl Ye Sni & $\begin{array}{l}\text { Total discouragement. Preoccupation with death, ghosts, spirits. Excessive drinking, suicide thoughts and attempts } \\
\text { (Sioux Indians). }\end{array}$ \\
\hline Uquamairineq & $\begin{array}{l}\text { Hypnotic states, disturbed sleep, sleep paralysis, dissociative episodes and occasional hallucinations (Native Alaskans: Inuit, } \\
\text { Yuit). }\end{array}$ \\
\hline
\end{tabular}

\section{Table 1}

Examples of Culture-Bound Disorders 


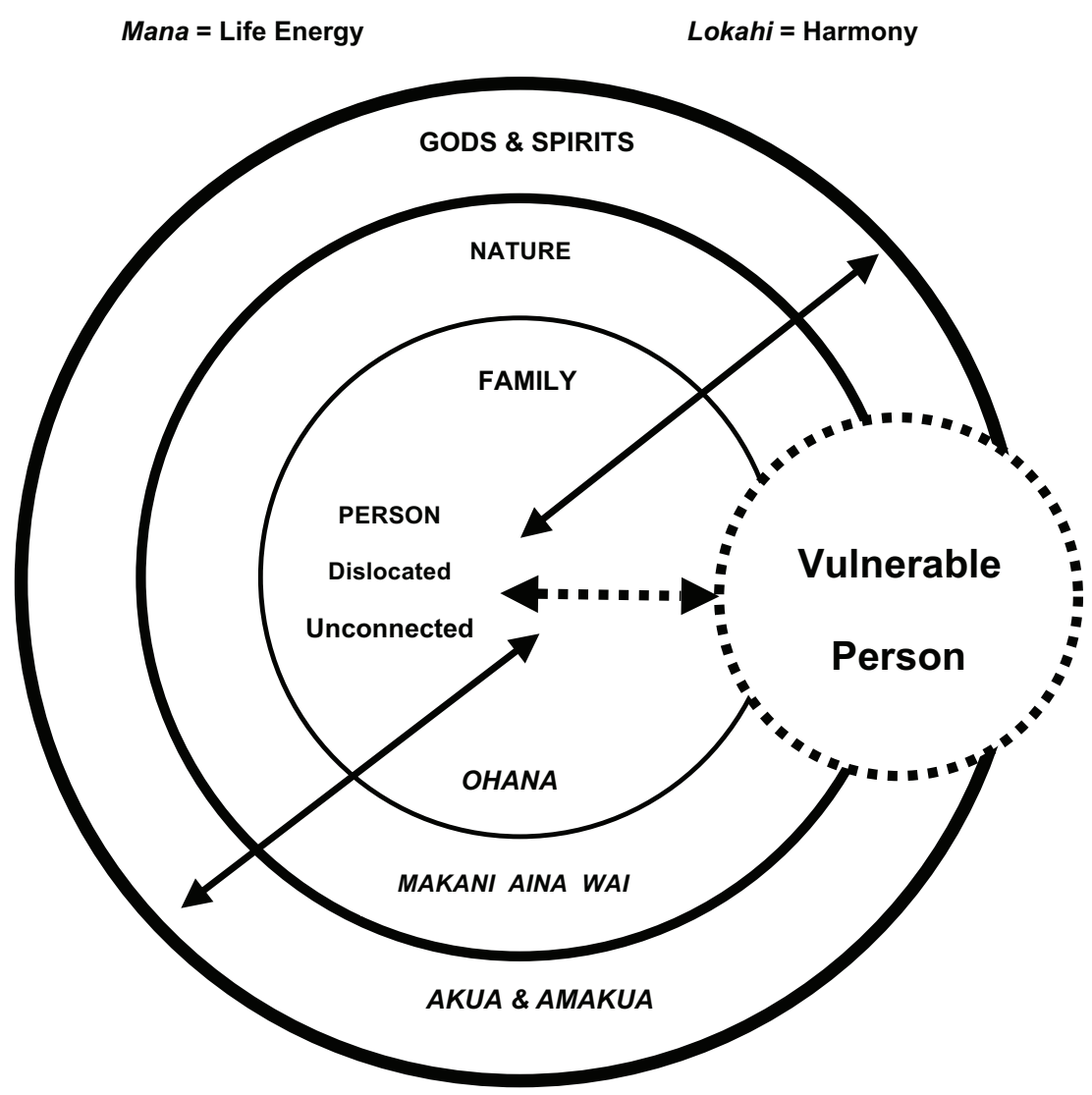

\section{Figure 1:}

Traditional Native Hawaiian Conception of Psyche: Person, Family, Nature, and Spiritual World.

Note: A person dislocated from the spiritual, nature, and social environmental, social, context becomes vulnerable to different patterns of maladjustment and deviancy. Healing involves restoring the person to the context and recovering mana and lokahi.

Source: McCubbin \& Marsella, 2009.

- Breaking promises (hua Olelo)

- Speaking bitter thoughts (waha 'awa)

- Stealing, fighting, and hostile (huhu) behaviour.

Destruction of the spiritual fabric occurs as forces come into play when an individual or a family violates certain taboos or restrictions, thus opening the door for supernatural forces seeking propitiation or mollification to enter their lives. These forces are:

- Offended ghosts (lapu)

- Natural spirits (kupua)

- Spirit guardians (aumakua)

- Ancestor/elders (kupuna)

- Black magic or sorcery (ana'ana)

- Curse (anai).

The resolution of both social and supernatural conflicts can occur by using prosocial behaviors and certain rituals that can restore and promote lokahi. Prosocial behaviors include adopting the behaviors of a Kanaka Makua (a good person); these behaviors include the following:

- Humility and modesty (ha'aha'a)
- Politeness and kindness ('olu’olu)

- Helpfulness (kokua)

- Acceptance, hospitality, and love (aloha).

Ritualistic behaviors that can restore and promote harmony include the following Native Hawaiian healing arts:

- Herbal treatments (la'au kahea)

- Purification baths (kapu kai)

- Massage (lomi lomi)

- Special diets and fasting

- Confession and apology (mihi)

- Dream interpretation (moe 'uhane)

- Clairvoyance (hihi'o)

- Prayer (pule ho'onoa)

- Transfer of thought (Ho 'olulu ia)

- Possession (noho)

- Water blessings ( pi kai)

- Spirit mediumship (haka). 
Thus, the Native Hawaiian worldview encompasses a complex system that is rooted in the interaction of body, mind, and spirit. It is directly tied to prosocial human relations and prospiritual relations. The restoration of health and wellbeing requires the adoption of prosocial behaviors and engagement in the healing arts and protocols that can reestablish interpersonal and psychological harmony. If violations occur, there are a number of dysfunctions or disorders that can occur including (see Marsella - E Ola Mau Mental Health Task Force Report, 1985):

- 'a'a:

- 'a aia:

- 'a ala'ioa:

- hehena:

- ho'ohewahewa:

- kaumaha:

- kuloloa:

- loha:

- lu’ulu'u:

- ma'ina loko:

- ma'ina waho:

- ohewa:

- opulepule:

- pupule:

- uluahewa:

- uluhia:

- uluhua:

- uluku:

- 'uhane noho:

- wela:
Panic stricken. Made dumb by anger and fury

Demented

Wild, uncontrolled

Insane, lunatic, crazy

Deranged (not as strong as hehena or pupule)

Sad, heavily burdened

Idiotic

Sullen, spiritlessness

Heavily burdened, sorrowful, troubled

Sickness from within (caused by misdeeds, family troubles)

Sickness from outside (evil forces, external cause)

Delirious, incoherent, drunk

Moronic, imbecilic

Crazy, insane, wild, uncontrolled

Crazy, sometimes due to evil spirit

Possessed by evil spirits

Irritated, vexed, annoyed

Disturbed, agitated, nervous

Possessed by a spirit

Angry (hot)

All of these outcomes are related to a person becoming dislocated or disconnected from the spiritual and social societal fabric as a result of violations. The healing then seeks to reconnect the person. Thus, the Native Hawaiian culture offers an excellent example of a non-Western approach to health and disorder and to the pathways to healing. It is, in our opinion, more sophisticated and substantive in its premises, assumptions, and terminology than Western psychiatric views that focus on reductionistic views locating problems within the individual brain.

\section{Cultural Considerations in Psychopathology}

Evidence points to the fact that cultural factors are critical determinants of the etiology (e.g., Leighton \& Murphy, 1961; Marsella, 1982). For example, consider

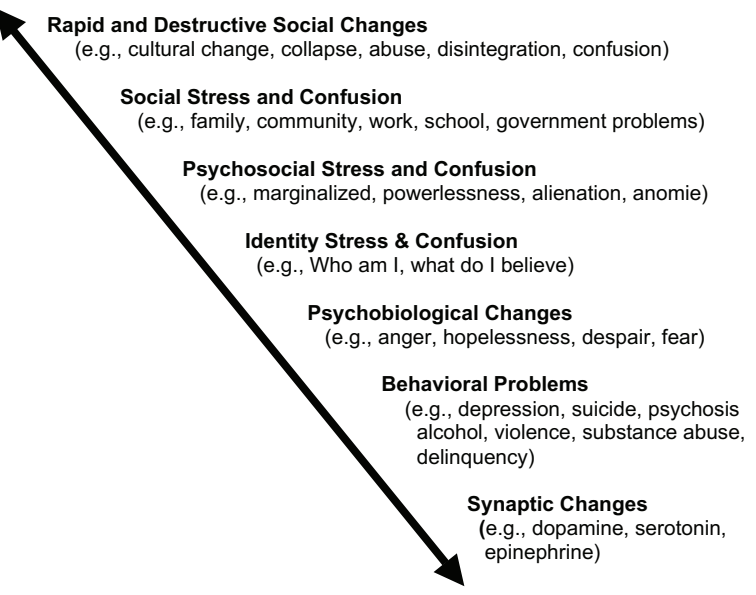

Figure 1

Sociocultural pathways to distress, deviance and disorder.

Source: Adapted from Marsella \& Yamada, 2007.

the following cultural processes in the etiology of psychopathology: Culture determines: (1) the patterns physical and psychosocial stressors, (2) the types and parameters of coping mechanisms and resources used to mediate stressors, (3) basic personality patterns including, but not limited to, self-structure, self-concept, and need/motivational systems, (4) the language system of an individual, especially as this mediates the perception, classification, and organisation of responses to reality, (5) standards of normality, deviance, and health, (6) treatment orientations and practices, (7) classification patterns for various disorders and diseases, (8) patterns of experience and expression of psychopathology, including such factors as onset, manifestation, course, and outcome.

While psychiatry and psychology continue to localise psychopathology in the brain, there is a failure to recognise that the context in which we live shapes the electrochemical forces that occur at the synaptic levels. Can anyone deny that events that occur macro-levels such as urbanisation, social change, violence and war leave no imprint on the brain or that the various stresses associated with family life, work, school, and neighborhood have no impact. Consider Figure 1, in which massive life-change events eventually impact the synapse resulting in various forms of psychopathology. Understanding the process by which events at higher levels shape events at lower levels (e.g., hierarchical systems) remains for greater study, but the impact is questionable.

Marsella and Yamada (2000) stated:

Mental health is not only about biology and psychology, but also about education, economics, social structure, religion, and politics. There can be no mental health where there is powerlessness, because powerlessness breeds despair; there 
can be no mental health where there is poverty, because poverty breeds hopelessness; there can be no mental health where there is inequality, because inequality breeds anger and resentment; there can be no mental health where there is racism, because racism breeds low self-esteem and self denigration; and lastly, there can be no mental health where there is cultural disintegration and destruction, because cultural disintegration and destruction breed confusion and conflict (Marsella \& Yamada, 2000, p. 10).

\section{Culture and Psychiatric Epidemiology}

\section{The Issue of Methodology}

It is an almost reflexive question in culture and psychopathology studies to ask whether rates of 'mental illness' differ across cultures. To be sure, there are many national and international reports of epidemiological studies of various disorders (e.g., DiGirolamo \& MacFarlane, 1996; Hopper, Harrison, Janca, \& Sartorious, 2008). However, there are so many complex issues involved in conducting psychiatric epidemiology studies that it may well be more just and judicious to acknowledge their requirements.

As we have pointed out, there are numerous issues involved in the assessment and diagnosis of mental illness across cultures. The issues make valid data collection a difficult task. Marsella (1979) and Marsella, Sartorious, Jablensky, and Fenton (1985) listed criteria that must be met before data can be compared. They stated that the comparative epidemiological studies must:

1. Use relevant ethnographic and anthropological data in designing an epidemiological study, especially in determining what constitutes a symptom or category or a case.

2. Develop glossaries of terms and definitions for symptoms and categories.

3. Derive symptom patterns and clusters using multivariate techniques rather than relying on simple a priori clinical categories.

4. Use similar/comparable case identification and validation methods.

5. Use culturally appropriate measurement methods that include a broad range of indigenous symptoms and signs that can be reliably assessed.

6. Establish frequency, severity, and duration baselines for Indigenous and medical symptoms for normal and pathological populations.

7. (Added 2009): Conduct case identifications using both Western and Indigenous conceptions and definitions. This will permit a determination of rates using Western, Indigenous, and overlaps

\section{Whose Criteria Will Be Used: What is a Case?}

These steps do not guarantee accuracy, but they do call attention to the complexities involved in conducting comparative epidemiological studies of mental illness. Failure to consider them can lead to destructive consequences for cultures under study since they may either overestimate or underestimate actual rates leading to faulty policy decisions and misleading stereotypes. Although cultures and nations do vary in terms of the stresses they impose on their members and resources available for dealing with these stresses, comparison data must meet stringent criteria or one group may be seen as pathological and another as salutogenic when the opposite may be the more accurate conclusion. Nevertheless, these considerations have not stopped researchers from doing both national and international epidemiology studies using Western criteria, seemingly oblivious to all we have suggested. Their results should be considered within the limitations described above (e.g., Weiss, 2001). Alarcon et al. (2002) echo the above in their words.

A crucial feature of the cultural epidemiologic context in relation to diagnosis is who decides on the values and priorities that transform findings into authoritative evidence. The cultural representation of mental illness requires a categorical identification but also a narrative account and a full assessment of the social context in which illness occurs. (p. 234)

\section{The 'Schizophrenic Spectrum' Disorders}

\section{Schizophrenia: A Problematic Term and Disorder(s)}

Of all the mental disorders, dysfunctions, and neurological disease that constitute the purview of mental health scientists and professionals, the schizophrenic disorders are the most problematic with regard to the accepted role of cultural influences. The debate and argumentation is extensive because of the strong position that schizophrenia is a universal disorder because of a biological etiology and there are few cultural influences in either its causation or clinical parameters. However, while research on biological aspects of schizophrenia continues to receive much, both financially and theoretically, the facts of the matter point to a very different conclusion.

Research projects by staff and research affiliates of the Division of Mental Health of the World Health Organization were set up to investigate rates, symptom patterns, clinical parameters such as onset, course, and outcome. Results form these studies all point to international variations in these areas, bewildering as this may be for many affiliated with the WHO projects because of their professional beliefs in biological positions and their support for DSM and ICD classification systems (e.g., Day, Nielsen, Korten, Ernberg, et al., 1987; Hooper, Harrison, Janca, \& Sartorius, 2007; Katz, Marsella, Dube, Olatawura, et al., 1988). 
Table 2

Some Socio-Cultural Determinants of Schizophrenia

1. Cultural concepts of personhood, and the related implications of this for individuated versus unindividuated definitions of selfhood and reality.

2. Cultural concepts regarding the nature and causes of abnormality, discomfort, disorder, deviance, and disease, and those regarding the nature and cause of normality, health, and wellbeing.

3. Cultural concepts and practices regarding health and medical care and prevention; attitudes toward illness and disease.

4. Cultural concepts and practices regarding breeding patterns and lineages.

5. Cultural concepts regarding pre-natal care, birth practices, and postnatal care, especially in such areas as nutrition and disease exposure.

6. Cultural concepts and practices regarding socialisation, especially family, community, and religious institutions, structures and processes.

7. Cultural concepts and practices regarding medical and health care especially with regard to the number and types of healers, doctors, sick-role status, and so on.

8. Cultural stressors such as rates of socio-technical change, socio-cultural disintegration, family disintegration, migration, economic development, industrialisation, and urbanisation.

9. Culturally related patterns of deviance and dysfunction, including trauma (PTSD), substance abuse, violence and crime, social isolation, alienation/anomie, and the creation of pathological and deviant subcultures.

10. Cultural stressors related to the clarity, conflicts, deprivations, denigrations, and discrepancies associated with particular needs, roles, values, statuses, and identities.

11. Cultural stressors related to socio-political factors such as racism, sexism, and ageism and the accompanying marginalisation, segmentalisation, and underprivileging.

12. Cultural resources and coping patterns including institutional supports, social networks, social supports, and religious beliefs and practices.

13. Cultural exposure to various risk conditions such as communicable diseases (e.g., viruses), toxins, dietary practices, population density, poverty, homelessness.

Source: Marsella et al., 2002.

\section{The Fault is in The Term Itself}

Literature reviews and commentaries on schizophrenia theory and research by the senior author of this article and his research team (Marsella, 1988; Marsella, 1999a; Marsella, Suarez, Morse, Leland, et al., 2002) summarise historical, conceptual, and empirical studies that document the fact that schizophrenic disorders vary considerably across cultural boundaries and that the source of this may be both actual and may reside in the very conceptualization of schizophrenia replete with all its excess definitions, meanings, patterns, and treatment responses. Should Table 2 presents a set of potential socio-cultural determinants of schizophrenia.

But perhaps what is even more relevant here is the fact that the study of schizophrenia continues to be burdened by numerous conceptual and methodological problems that have not been solved in spite of the efforts to develop diagnostic criteria in the DSM and ICD manuals. There are too many issues that interfere with accurate diagnosis. Table 3 lists 14 continuing conceptual issues that are relevant for cross-cultural and international research but also for research within the Western nations who continue to support the use of the 'concept' of schizophrenia.

\section{Some Closing Concerns and Issues The Issue of Cultural Competence}

Cultural competence has become a popular term in the mental health fields as ethnic minority groups called for increased knowledge and sensitivity of their culture in rendering various services. Competence, of course, refers to the capacity to perform a particular task according to certain expected high standards that ensure quality. Cultural competence means the capacity to render quality services to different cultural groups because of increased knowledge of their culture's history, knowledge, ways of life. Appendix A provides a checklist for assessing one's cultural competence by replying to a series of questions on various aspects of a culture including history, language, food, and so on.

Historically, concern for culture competence in the United States can be traced to 1950s when White dominance and its accompanying racism showed little support for the rights of people of color, women, and LBGT groups. Segregation was still widely practised. The 1954 Brown $v$ Board of Education (Kansas) decision by the Supreme Court led to national equal rights - everyone must be treated the same. But, this did little to promote 'competence' in working with our diverse ethnic minority populations. It was the 1960s that brought the issue to the foreground as civil rights protests, 'Black is Beautiful' movements, the rise of feminism, cultural studies, and post-colonial wars (e.g., Kenya) raised consciousness about the need to understand diversity. Between the 1970s and the present, issues of 'ethnocentricity', ethnic identity, and various legal actions encouraged 'cultural competence' to emerge, not as a legal imposition within the mental health professions, but as a requirement for effective services and practices.

Madeleine Leininger (1978), a professor of transcultural nursing, was among the first to call for cultural 


\section{Table 3}

Fourteen Continuing Issues in the Conceptualisation of Schizophrenia

1. Are there different subtypes of schizophrenia which share a common cause? (Issue of Equifinality)

2. Are there different causes of schizophrenia that share a common expression? (Issue of Equipotentiality)

3. Are there different subtypes of schizophrenia, each of which have different causes and expressions? (Issue of Heterogeneity in Cause, Expression, \& Classification)

4. Are there variations in the course of different 'subtypes' of schizophrenia? (Issue of Variation in Course)

5. Are there variations in the outcomes of different 'subtypes' of schizophrenia? (Issue of Variations in Outcome)

6. Can schizophrenia(s) be reliably diagnosed? (Issue of Diagnostic Consistency)

7. Should the manic-depressive psychosis/bipolar disorder be considered a separate psychosis from schizophrenia(s) or is this an artifact of Kraepelin? (Issue of Arbitrary Separation of Cognition and Affect Traceable to Kraepelin)

7. Is there a spectrum of schizophrenic disorders with varying genetic-environmental etiologic penetrations?

8. Is schizophrenia continuous or discontinuous with normal personality and behavior? (Issue of Distinct Categories or Continuums of Disorder)

9. What are the specific basic deficits in schizophrenia(s) - social, psychological, biological, or interactive? (Issue of Locus of Deficit)

10. Are clinically-based diagnostic and classification systems of schizophrenia useful for predicting therapeutic and preventive functions? (Issue of the Value of Diagnosis for Prediction and Prevention)

11. Is schizophrenia a universal or a culture-specific disorder? (Issue of Variations in the Sources of Behavioral Plasticity)

12. How can we best understand the contributions of formative, precipative, exacerbative, and maintenance causes in schizophrenia(s)? (Issue of Multiple and Multiplicative Causality)

13. Can a reliable and valid diagnosis of schizophrenia(s) be made on the basis of presenting symptomatology, clinical history, and other clinical parameters? (Issue of Necessary, Adequate and Sufficient Diagnostic Criteria)

14. Can any single theory (i.e., genetic, biochemical, anatomical, psychological) account for the extensive variations in onset, manifestation, course, outcome, and/or treatment responsivity (Issue of Variation in Etiology and Clinical Parameters)

15. Do rates of schizophrenia vary across nations, cultures and historical periods? (Issue of Epidemiological Distribution)

Source: Marsella, 1995; Marsella et al., 2002.

competence in her volume on transcultural nursing, in which she proposed new standards for working with ethnically diverse groups. Pedersen and Marsella (1982) subsequently called for changes in the American Psychological Association Code of Ethics because of biases and cultural insensitivities in the ethical guidelines. Other publications by Cross, Bazron, Dennis, \& Isaacs (1989) made explicit calls for culturally competent health care systems in working with children, and the Office of Minority Health of the United States Department of Health and Human Services (DHHS) advanced guidelines on the provision of health care services to culturally and linguistically diverse groups. Dana and Allen's (2008) volume, Cultural Competency Training in a Global Society, provides a comprehensive overview of cultural competency and its importance for mental health services in a global community.

\section{The Multiple Determinants of Human Behavior}

As scientists and practitioners, mental health professionals must seek the determinants of psychopathology in its many forms and manifestations among many different sources of causality. No single cause has ever been sufficient to describe, explain, or predict psychopathology be it biological, psychological, or social. In so many ways, the early words of Clyde Kluckholm \& Henry Murray (1950) offer us important insights regarding this issue. Kluckholm was an anthropologist and Murray a physician and psychologist, problem when they opened their classic volume, Personality in Nature, Culture, and Society, with the following words (Kluckholm \& Murray, 1950).

We are like all other men (sic)

We are like some other men (sic)

We are like no other man (sic). (frontispiece)

Think about it! We are like 'all' other men (sic) in various aspects of our biology including various anatomical structures and physiological processes and their implications for adjustment and adaptation. We are like 'some' other men with respect to various diversity markers, especially those related to ethnicity, gender, marital status, religion, and other cultural expressions. And we are like 'no' other men with regard to our unique and distinct genetic heritage and lived experience, which contributes to our unique temperament and personality.

Within the mental health sciences and professions, governed as they have been by psychiatry with its preferences for biological and related reductionistic determinants, and by psychology, with its preferences for personality and cognitive determinants, the 'cultural' perspective has had to struggle for recognition and acceptance. Today, interest and concern for the cultural determinants of psychopathology occupies a new position of authority that challenges the biological and psychological perspectives to acknowledge has 'cultural variations' in rates, expressions, diagnosis/classification, course, outcome, and treatment of psychopathology. Failure to 
accept these unassailable facts increases the risks of erroneous and potentially destructive clinical decisions.

There is nothing admirable about a rigid mindset that denies alternatives because of an intolerance of ambiguity. It isn't even good science, since good science progresses from doubt, not certainty (Marsella, 1999b). Even as we evidence preferences for particular theoretical and conceptual viewpoints, it is incumbent that we do so with tentativeness. The study of culture and psychopathology has revealed how our clinical knowledge and practice is often shaped not by science, but by social and political forces that are in a position to advance particular views based on their ethnocentric or gender biases. We are not free of this risk, but we are now much more aware of it now and thus capable of responding to it with corrective and preventive measures. For ethnic minorities in the United States, and for the entire international community, the expanded consideration of cultural factors in psychopathology research and service provision has introduced new hope and opportunities that diagnostic and treatment errors will be reduced leading to improvements in the accessibility, availability, and acceptability of care across cultural boundaries (see Marsella \& Yamada, 2007).

\section{References}

Alarcon, R., Alegria, M., Bell, C., Boyce, C., Kirmayer, L., Lin, K.M., et al. (2002). Beyond the funhouse mirrors: Research agenda on culture and psychiatric diagnosis. In D. Kupfer, M. First \& D. Regier (Eds.). A research agenda for DSM-V (pp. 219-282). Washington, DC: American Psychiatric Press

American Psychiatric Association. (1994). Diagnostic and statistical manual. of mental disorders. Fourth edition. Washington, DC: American Psychiatric Press.

American Psychological Association. (1992). Guidelines for providers of psychological services to ethnic, linguistic, and culturally diverse populations. American Psychologist, 48, 45-48.

Blashfield, R. (1984). The classification of psychopathology: NeoKraepelinian and quantitative approaches. New York: Plenum Press.

Chakraborty, A. (1991). Culture, colonialism, and psychiatry. The Lancet, 337, 1204-1207.

Cross, T.L. Bazron, B., Dennis, K, \& Isaacs, M. (1989). Towards a culturally-competent system of care: A monograph of effectve services for minority children who are severely emotionally disturbed. Washington, DC: Georgetown University Child Development Center.

Dana, R., \& Allen, J. (2008). Cultural competence training in a global society. New York: Springer SBM Publications

Day, R., Nielsen, J., Korten, A., Ernberg, G., Dube, K., Gebhart, J., et al. (1987). Stressful life events preceding the acute onset of schizophrenia: A cross-national study from the World Health Organization. Culture, Medicine, and Psychiatry, 11, 1-123.

Department of Health and Human Services (2001). Culture, race, and ethnicity. Washington, DC: Author.
DiGirolamo, G., \& MacFarlane, A. (1996). The epidemiology of PTSD: An international review of the literature. In A.J. Marsella, M. Friedman, E. Gerrity, \& R. Scurfield (Eds.) Ethnocultural aspects of PTSD: Issues, research, and clinical applications (pp. 33-86). Washington, DC: American Psychological Association Press.

Draguns, J. (2006). Culture in psychopathology - psychopathology in culture. In T. Plante (Ed.), Mental disorders of the new millennium: Public and social problems (Vol 2., pp. 215-233). Westport, CT: Praeger.

Durant, W., \& Durant, A. (1967). Rousseau and revolution. Story of civilzation: Part X. New York: Simon \& Schuster

Fabrega, H. (2001). Culture and history in psychiatric diagnosis and practice. In J. Mezzich, J., \& H. Fabrega, H. (Eds.), Cultural psychiatry: International perspectives (pp. 391406). Philadelphia, PA: W.B. Saunders

Higginbotham, H., \& Marsella, A.J. (1988). International mental health consultation and the homogenization of third-world psychiatry. Social Science and Medicine, 27, 553-561.

Higginbotham, H., Takeuchi, D., Marsella, A.J., Gomes, K., Kwan, L., Ostrowski, B., et al. (1987). Native Hawaiian mental health. In Robillard and A.J. Marsella (Eds.), Contemporary issues in mental health research in The Pacific Islands. Honolulu, HI: SSRI (University of Hawaii Press).

Hooper, K., Harrison, G., Janca, A., \& Sartorious, N. (2007). Recovery from schizophrenia: An international perspective. New York: Oxford University Press.

Jones, E. (1953). The life and work of Sigmund Freud. New York: Basic Books.

Katz, M., Marsella, A., Dube, K., Olatawura, M., Takahashi, R., Nakane, Y., et al. (1988). On the expression of psychosis in different cultures: Schizophrenia in an Indian and in a Nigerian community. Culture, Medicine, and Psychiatry, 12, 331-355.

Kleinman, A. (1980). Patients and healers in the context of culture: An exploration of the borderland between anthropology, medicine, and psychiatry. Berkeley, CA: University of California Press.

Kleinman, A., \& Good, B. (1985). Culture and depression. Berkeley, CA: University of California Press.

Kluckholm, C., \& Kroeber, A. (1952). Culture: A critical review of concepts and definitions. Cambridge, MA: Peabody Museum.

Kluckholm, C., \& Murray, H. (1950). Personality in nature, culture, \& society. New York: Basic Books.

Kraepelin, E. (1904). Vergleichende psychaitrie. Zentralblatt fur Nervenherlkande und Psychiatrie, 15, 433-437.

Leighton, A., \& Hughes, J. (1961). Cultures as causative of mental disorder. In Causes of mental disorders: A review of epidemiological knowledge. New York: Milbank Memorial Fund.

Leininger, M. (1978). Transcultural nursing: Concepts, theories, and practices. New York: John Wiley.

Leininger, M. (1983). In P. Pedersen, N. Sartorius \& A.J. Marsella (Eds.), Mental health services. The cultural context (pp. 109-134). Beverly Hill, CA: Sage 
López, S.R., \& Guarnaccia, P.J. (2008). Cultural dimensions of psychopathology: The social world's impact on mental disorders. In J. Maddux \& B. Winstead (Eds.), Psychopathology: Foundations for a contemporary understanding (2nd ed., pp. 19-38). New York: Routledge/Taylor \& Francis Group.

Marsella, A.J. (1979). Thoughts on cross-cultural studies on the epidemiology of depression. Culture, Medicine, and Psychiatry, 2, 343-357.

Marsella, A.J. (1982). Culture and mental health: An overview. In A.J. Marsella \& G. White (Eds.), Cultural conceptions of mental health and therapy (pp. 359-388). Boston, MA: G. Reidel Press.

Marsella, A.J. (1985). Culture, self, and mental disorder. In A.J. Marsella, G. DeVos \& F. Hsu (Eds.), Culture and self: Asian and Western perspectives (pp. 279-308). New York and London: Tavistock Publications.

Marsella, A.J. (1988). Cross-cultural research on severe mental disorders: Issues and findings. Acta Psychiatrica Scandinavica, 78, 7-22.

Marsella, A.J. (1993). Sociocultural foundations of psychopathology: A pre-1970 historical overview. Transcultural Psychiatric Research and Review, 30, 97-142.

Marsella, A.J. (1997, February). The plight of the Native Hawaiians. Paper presented at the Native Hawaiian identity and acculturation. Union of Polynesian Nations Conference, East-West Center, Honolulu, Hawaii.

Marsella, A.J., (1999a). Conceptual and methodological issues in schizophrenia research and practice. In T. Hallstrom \& S. Ekblad (Eds.), Progress in psychopathology: Festschriften fur Professor Bengt Jansson. Stockholm, Sweden: Karolinska Institute

Marsella, A.J. (1999b). In search of meaning: Some thoughts on belief, doubt, and well being. The International Journal of Transpersonal Studies, 18, 41-52.

Marsella, A.J. (2000). Culture-bound disorders. In A. Kazdin (Ed.), The encyclopedia of psychology (pp. 407-410). Washington, DC: American Psychological Association Press/Oxford University Press.

Marsella, A.J. (2009). Abuses of psychology's knowledge and practices. Psychological Studies, 1, 10-15.

Marsella, A.J., Gomes, K., Kwan, L., Ostrowski, B., Rocha, B., Wight, K. (1985). Native Hawaiian mental health. E Ola Mau Task Force Report. Honolulu, HI: Alu Like

Marsella, A.J., \& Yamada, A. (2000). Culture and mental health: An overview. In I. Cuellar \& F. Paniagua (Eds.), Handbook of multicultural mental health: Assessment and treatment of diverse populations (pp. 3-26). New York: Academic Press.

Marsella, A.J., Oliviera, J., Plummer, M., \& Crabbe, K. (1995). Native Hawaiian culture, mind, and wellbeing. In $\mathrm{H}$. McCubbin, E. Thompson, \& A. Thompson (Eds.), Stress and resiliency in racial and minority families in America. (pp. 93-114). Madison, WI: University of Wisconsin Press.

Marsella, A.J., Sartorius, N., Jablensky, A., \& Fenton F. (1986). Culture and depressive disorders. In A. Kleinman \& B. Good (Eds.), Culture and depression (pp. 299-324). Berkeley, CA: University of California Press.

Marsella, A.J., \& Yamada, A. (2007). Culture and psychopathology. In S. Kitayama, \& D. Cohen, (Eds.) Handbook of cultural psychology (pp. 3-26). New York: Guilford Publications.

Marsella, A.J., Suarez, E., Morse, H., Leland, T., Scheuer, A., \& Digman, B. (2002). Cross-cultural aspects of schizophrenic disorders. In H. Bot, M. Braakman, L. Preijde, et al. (Eds.), Culturen op de vlucht [Cultures for those in transition] (pp. 47-76). Amsterdam: Phoenix Press.

McCubbin, L., \& Marsella, A.J. (2009). Native Hawaiian culture and behavior: The cultural, historical, and situational context of knowing and being. Cultural Diversity and Ethnic Minority Psychology, 15, 374-387.

Murray, H., \& Kluckholm, C. (1953): Personality in nature, culture, and society. New York: Basic Books.

Office of Minority Health (DHHS) (2000). National standards for culturally and linguistically appropriate services in health care. Final Report. Office of Minority Health United States Department of Health and Human Services (DHHS). Rockville, Maryland.

Paniagua, F. (2001). Diagnosis in a multicultural context. Thousand Oaks, CA: Sage.

Pedersen, P, \& Marsella, A.J. (1982). The ethical crisis for crosscultural counseling and therapy. Professional Psychology, 13, 492-500.

Simons, R., \& Hughes, C. (Eds.) (1985). The culture-bound syndromes. Boston, MA: G.Reidel/Kluwer Publications.

Weiss, M. (2001). Cultural epidemiology: An introduction and overview. Anthropology and Medicine, 8, 5-29.

Yamada, A.-M., \& Brekke, J. (2008). Addressing mental health disparities through clinical competence not just cultural competence: The need for assessment of sociocultural issues in the delivery of evidence-based psychosocial rehabilitation services. Clinical Psychology Review, 28, 1386-1399. 


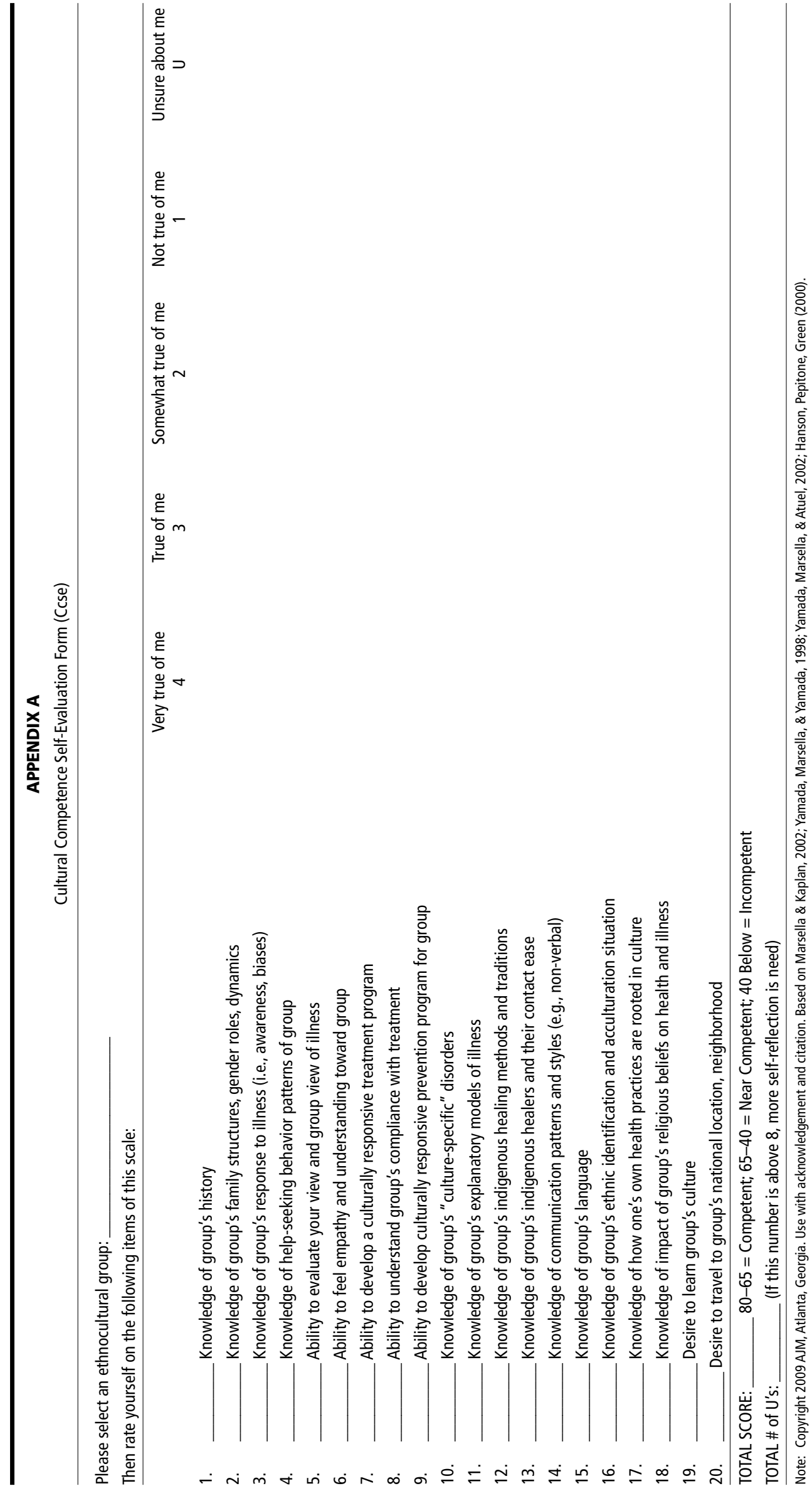

